\title{
FEW CLIMATE CHANGE STUDIES ASSESSMENT ACROSS THE GLOBE
}

\author{
Ganesh D. Kale \\ Civil Engineering Department, S. V. National Institute of Technology, Surat, Gujarat, India
}

\begin{abstract}
The climate change is undisputed as known from the various published literature. So in present study, various case studies of effect of climate change on water resources across the globe are reviewed while focusing on methodology used and major impacts, by dividing them on the basis of continents. In America continent, some studies assessed effect of climate change through chain of GCM-downscaling-rainfall-hydrologic model-runoff while few assessed climate change impact through trend studies. Many studies have shown increase in winter runoff and decrease in summer runoff. In Europe continent, few studies assessed effect of climate change through the chain of GCM-dynamic downscaling-rainfall-hydrologic model-runoff and use of synthetic scenarios with water balance models. No study assessed climate change impact through trend detection. Many studies indicated increase in winter runoff and decrease in summer runoff. Arnell (1999) found that drought intensity will increase in Western Europe and decrease in North and East Europe. In Asia continent, very few studies assessed effect of climate change through the chain of GCMdownscaling-rainfall-hydrologic model-runoff and use of synthetic scenarios or GCM derived scenarios with water balance models while few assessed climate change impacts through trend studies. Many studies have concluded increase in winter runoff and reduction in summer runoff. From the present study, it is concluded that, number of case studies from America, UK, China were more as compared to other countries. No studies were carried out with all IPCC GCMs, scenarios, downscaling methods. So, complete assessment of uncertainty is difficult, without which appropriate adaptation measures cannot be specified and carried out.
\end{abstract}

Keywords: Climate change, Uncertainty, Assessment of climate change studies

\section{Introduction}

The increased population, fossil fuel use and industrialization have resulted in increased green house gas concentrations in atmosphere leading to climate change. Climate change is defined as alteration in the state of climate identified by changes in the value of mean and/or variability of properties of climate which persist for long period, typically decades or more (Hegerl et al., 2007).

The climate change is undisputed as known from the various published literature. From the observations of rising global average temperatures of air and ocean, large scale melting of ice and snow cover and increased average sea levels of world, it is undisputed that the climate change has been took place (IPCC, 2007). Bates et al. (2008) stated that "Observational records and climate projections provide abundant evidence that freshwater resources are vulnerable and have the potential to be strongly impacted by climate change, with wide-ranging consequences for human societies and ecosystems". Labat et al. (2004) clearly indicated the acceleration of global hydrological cycle due to global warming. Dyurgerov and Meier (2000) found shift in the trend of glacier volume change in mid 1970s with further rapid change in the last decade which was consistent with the climatological data. Also the rise of temperature of air as suggested by glacier temperature sensitivity in cold regions was greater than the global mean temperature uprise obtained from the gauges at low altitude, which had shown sign of accelerated warming. 
Doll (2002) found that two third of the irrigated area of world equipped with the irrigation facility in 1995 will face the increased irrigation demands while half of the global irrigated area will be significantly affected by the negative effects of global climate change as against the climate variability.

Askew (1987) presented consideration of climate impact on water resources in wider context. It consists of associated chain reactions with such an impact crossing the interface among climate, hydrology, systems of water resources and finally society. So, assessment of few climate change studies across the globe is performed to derive meaningful conclusions regarding the shortcomings on the part of studies and to focus on the research avenues for further work. For sake of easiness the case studies are divided on the basis of continent.

\section{Literature Review}

Climate change case studies are grouped on the basis of continents to derive meaningful conclusions.

\section{Studies from America Continent}

Nemec and Schaake (1982) demonstrated the sensitivity of water resources system to climate variation by the use of stationarity of mean and extremes. The deterministic modeling of effect of climate variation on stream flow was performed in dry Pease River Basin of U.S.A., humid Leaf River Basin near Mississippi, U.S.A and basin of Lake Victoria in Africa. The deterministic Sacramento Soil Moisture Accounting Model, which is considered as the most reliable model under the conditions of climate variations was used for modeling of streamflow by giving daily time step input of precipitation and evapotranspiration. For future, climate scenario inputs were multiplied by constant factor. The two climate change scenarios used were: variation of temperature by $\pm 1^{\circ} \mathrm{C}$ and $+3{ }^{\circ} \mathrm{C}$ and variation of precipitation by $\pm 10 \%$ and $25 \%$. The results obtained from the deterministic modeling of effect of climate variation on streamflow were used for the modeling of effect of variation of climate on reservoir storage systems. Model indicated the significant amplification of climate variation effect on runoff and storage of water resources systems.

Gleick (1987) used modified water balancing techniques for assessing climate change impacts at a watershed of Northern California using scenarios of climate change. The climate change scenarios were included the state of the art scenarios along with the series of hypothetical scenarios. The scenarios used in the study were 10 hypothetical scenarios like combination of $+2^{\circ} \mathrm{C}$ and $+4^{\circ} \mathrm{C}$ change in temperature and $0, \pm 10 \%, \pm 20 \%$ change in precipitation along with eight state of the art scenarios predicted by three general circulation models like Geophysical Fluid Dynamics Laboratory (GFDL), Goddard Institute for Space Studies (GISS) and National Centre for Atmospheric Research (NCAR) CCM. Results of the study have shown significant changes in the temperature and precipitation due to increase in trace gas concentrations in the atmosphere. These changes in temperature and precipitation may affect the runoff and soil moisture content of the significant agriculture areas. Similarity among all scenarios predictions was the existence of similar pattern of summer soil moisture drying with reduction of soil moisture about $8 \%$ to $44 \%$. Also increase of runoff in winter and reduction in summer runoff was found in the study.

Impact of climate change on levels of Laurentian Great Lakes and water management policies was studied by Hartmann (1990). Water supplies to the lake were derived from the linking climate change scenarios of general circulation models to conceptual models to estimate runoff, evaporation and precipitation on lake. Water supply components were used along with the operational regulation plans and models of hydraulic routing of outlet and linking channel flows to water levels of Lake Superior, Michigan, Huron, St. Clair, Erie and Ontario. Three steady state scenarios of climate change, modeling doubling of $\mathrm{CO}_{2}$ concentrations in atmosphere were compared to steady state simulations derived from historical data presenting unchanged atmosphere. The study revealed the implications of climate change as reduction of stream flows, reduction in consistent availability of marshes, fish and wildlife, reduction in hydropower production, increase in shipping cost and traffic, adverse effects on national, regional industries and commercial establishments, adverse effects on recreation, significant increase in problem of insect and disease in winter, expansion of agricultural 
activities in the Northern part of Great Lakes due to favorable growing conditions because of increased air temperatures.

Rogers (1994) stated that information regarding the future water availability, future water demand and effect of these two factors on the environment is essential for dealing with water resources. The introduction of anthropogenic climate change possibility will expand information required for inclusion of climate change effect on water availability. The study had reviewed the state of the knowledge about climate change effect on U.S.A. water resources. The study concluded existence of large uncertainties in prediction of water availability and even more uncertainties in forecast of socio-economic water demands. So, the prediction of U.S.A. water resources problems for next few decades due to climate change was found to be difficult.

Southeastern and Southwestern continental United States historical climate scenarios derived from 41 years data were applied in hydrological models of Great Lakes by Croley II et al. (1996) to assess the possible changes in variability linked with different hydrological conditions. Conceptual models of Great Lakes Environmental Research Laboratory (GLERL) were used for simulation of moisture storages and 121 watersheds runoff draining in to Laurentian Great Lakes, precipitation over each lake, heat storage in each lake and evaporation from each lake. Aforesaid components were combined by GLERL as each lake net water supplies, estimated levels of lake and linking channel flows to consider the climate scenarios transposed. Four climate zones were transposed ranging from $6^{0}$ south to $0^{0}$ west and $10^{0}$ south to $11^{0}$ west of the Great Lakes, to the area of Great Lakes. These transposed zones represent analog climate which could occur over the basin of Great Lakes under the global warming scenario. This transposition of climate zones was essential as it was incorporating the natural changes in the climate variability. The study had shown increase in average air temperature from $4^{0}$ to $11^{0} \mathrm{C}$, change in precipitation as compared to current climate was ranged from $80 \%$ to $170 \%$ over different lakes under different scenarios. This may result into decrease in water supply of whole water basin as compared to existing by $1 \%$ to $54 \%$. The higher air temperatures under the scenarios of transposed climate led to higher evapotranspiration over land and reduced runoff with earlier peaks because of $100 \%$ reduction in snow pack. This was resulted further in to reduction in available moisture in soil. Also the study shown increased and earlier peaked water temperatures, increased resident heat in deep lakes during whole year, mixing of diminished water columns, lakes becoming monomictic, increased lake evaporation. Water supplies were found to be decreased for the two driest scenarios with Lake Superior being terminal lake. The lake level variability was also found to be increased for most of the scenarios for all lakes. Maximum lake levels simulated were found to cross the recorded maximum lake levels for many scenarios on the lower lakes.

The impact of climate change on the performance of six water resources systems in U.S. exhibiting a wide range of variety in geographical, hydrological, institutional and social settings was studied by Lettenmaier et al. (1999). Columbia River, Missouri River, Apalachicola-Chatahoochee-Flint (ACF) River represented multiple reservoir systems while Tacoma and Boston Rivers represented the small reservoir systems. Medium size systems were represented by the Savannah River. The general circulation models (GCMs) output obtained after applying simple downscaling method was used as input to hydrological model and output of hydrological models was used as input to water resources models to know the impact of climate change on water resources. Study found out the sensitivity of six water resources systems to alteration in precipitation, solar radiation and temperature. The GCMs used were GFDL, United Kingdom Meteorological Office (UKMO) and Max Planck Institute (MPI). The scenarios used for the study closely resembled to IS92a scenario. Results of the study have shown that those river basins like Tacoma Basin, Columbia Basin, Missouri Basin and some extent Boston Basin were having significant amount of snow cover influenced with significant changes in seasonal streamflow hydrographs due to temperature change. In Savannah and ACF River systems, the hydrological changes were found to be more related to changes in temperature and precipitation. For stream flow, one transient scenario had shown decrease while other had shown increase at most of the sites. Also it was found that the effect of non climatic factors like increase in demand and other plausible future considerations of operation were equaled or exceeded the effect of climate change on the water resources system performance in future. 
The effect of climate change and climate variation on sensitivity of hydrology and water resources of the MidAtlantic Region (MAR) of United States was studied by Neff et al. (2000). Observed stream flow, water quality and ground water data were found to vary with climate variation. Projections of future stream flow, water quality and ground water were simulated using two scenarios derived from transient general circulation models. The scenarios used were Canadian Climate Centre scenarios and Hadley Centre scenarios. Regional streamflow was found to be increased for one scenario while decreased for the other. But the alteration in seasonality of peak flows was common for both the scenarios. The response of ground water to change in climate was found to depend upon the GCM scenario applied. The Canadian Climate Centre (CCC) scenarios projected earlier recharge resulting in to less extreme seasonal fluctuations in the levels of ground water while Hadley Centre scenario suggested more extreme seasonal fluctuations in ground water levels. But both these scenario predicted increase in the nutrient loads because of increased streamflow in winter and spring. Opposite process would occur in late summer. Further increased streamflow was found to create problems like maintaining low water levels in dam reservoirs, protection of water and sewage treatment plants from floods, groundwater surcharge's greater frequencies in low lying Karst landscapes and septic disposal system's failure.

Collischonn et al. (2001) performed analysis of measured flow at 20 sites, 36 sites of rainfall measurement and 95 year water level record at one site in Paraguay River Basin which shown that the flow regime of Paraguay River for period 1960-1970 was substantially different from the flow regime before and after. The long record of water levels in Ladario, Brazil shown that alterations between one period and next were significantly abrupt and not only that year to year structures of correlation and mean water levels within the record were also different. Since 1970 increased stream flow was due to increased annual rainfall frequency as compared to long term mean rainfall. Detailed assessment of characteristics of daily rainfall at two rain gauge stations had shown persistence of dry spells during low flows and smaller magnitude of rainfall during periods of rainfall. At these two rain gauge stations, the complete record was available for the period 19601970. Comparison of results of the study by Collischonn et al. (2001) with the results of other studies had shown strong evidences of alterations in the regimes of runoff in the la Plata Basin during the period of last 40 years, not all of which were attributed to changes in land use alone because of availability of complementary evidence of rainfall regime change. Findings of Congo Basin of Africa were also compared with the results of the study. The comparison had shown the similarity in the nature of results of both the basins. The study revealed existence of little relationship between the rainfall and runoff changes in the Paraguay River Basin with the ENSO, so needed other explanations for the same.

Simonovic (2003) prepared modeling framework for the assessment of effect of variation of climate and impacts of climate change on flood protection system of Winnipeg city in the basin of Red River, Manitoba, Canada. The model framework was such that it was allowing evaluation of different scenarios of climate change obtained from different global climate models like Hadley Centre Model 3 (HadCM3), Canadian General Circulation Model 1 (CGCM1), and ECHAM4. Scenarios used were $1 \%$ increase in $\mathrm{CO}_{2}$ concentration and $1 \%$ increase in $\mathrm{CO}_{2}$ concentration with sulphate aerosols. The temperature and precipitation were found to be dominant factors affecting the generation of flood flow. The essential feature of this study was the application of approach of system dynamics modeling and simulation used for the development of model for system performance assessment. This assessment modeling framework was dependent on flood flows, flood control structure capacity and flow levels of failure at different places in basin. The study indicated probable increase in annual precipitation and annual stream flow in the basin of Red River with earlier timings of flood starting and peak of flood. The study had shown that the capacity of Red River flood protection system was capable of handing future climate change and climate variability for low reliability criteria and increase of flood protection capacity in future was warranted under the criteria of high reliability.

The "end to end" assessment of climate change impact on western United States was performed by Barnett et al. (2004). The study was focused on the effect of climate change over first fifty years of $21^{\text {st }}$ century on Columbia, Colorado and Sacramento/San Joaquin River Basins. This study was consisting of three elements. First element consisted use of existing observations of ocean and inverse techniques to establish the observed global ocean physical state towards the end of $20^{\text {th }}$ century. This information in first element was used as 
initial condition for coupled global climate model to generate the scenarios of climate change for the $21^{\text {st }}$ century, which formed the second element. Third element was consisting of downscaling of large scale global model projections as ensembles of projections at regional scale in western United States. These regional scale projections were used for determining the impact of climate change on the local water availability and water dependent activities such as hydropower generation, stream habitat and irrigated agriculture. The coupled global climate model used was Parallel Climate Model (PCM) and downscaling methods used were the dynamic downscaling and statistical downscaling. Study had shown that by the mid century, the Colorado River Reservoir System will unable to fulfill the all demands like Southern California water supply and inland Southwest water supply because of one third reductions in reservoir levels and $17 \%$ decrease in the releases from the reservoir. Also all users of hydroelectric power generated from Colorado River will be affected because of reduced reservoir levels. In the Central Valley of California it may not be possible to meet performance levels of existing water system along with reduced reliability of: deliveries of water supply, production of hydropower and in-stream flows. Reduced snow pack and earlier runoff will decrease the ability of Yakima River in Washington state to meet the irrigation needs in summer, higher temperatures of water and increased conflict among the agricultural users. Also main concern was sustaining the endangered population of fish.

Impacts of climate change on western U.S.A. water resources were studied by Leung et al. (2004) with the help of simulations of climate produced by PCM of National Centre for Atmospheric Research/Department of Energy (NCAR/DOE). Downscaling of PCM control and future climate scenarios was performed using Penn State/NCAR Mesoscale Model (MM5). The basins selected for the study were Columbia River Basin (CRB) and Sacramento San Joaquin (SSJ) River Basin of U.S.A. Results of the general circulation models and regional climate models showed that by mid century the snowpack in western U.S. will get strongly affected by average regional warming of $1^{0} \mathrm{C}-2.5^{\circ} \mathrm{C}$. The annual snowpack reduction of about $70 \%$ was projected along the coastal mountains of U.S.A. The more rain on snow events were found to occur in the CRB. Overall effect of climate change was found to be increased flooding in winter and decrease in runoff and soil moisture in summer. Changes in surface temperature were governing changes in the surface water and budget of energy in both the basins at 0.95 confidence level.

The potential effects of climate change on water resources and hydrology of the Colorado River Basin were examined by Christiansen et al. (2004) through comparison of the simulations of hydrology and water resources scenarios obtained from downscaled climate simulations of Parallel Climate Model of U. S. DOE/NCAR and scenarios obtained from observed historical climate of period 1950-1999. Downscaled transient sequences of temperature and precipitation were derived from PCM simulations and were used to drive one macro scale hydrological model, Variable Infiltration Capacity (VIC) to produce corresponding sequences of stream flow. Results of study for "business-as-usual" scenarios were summarized for the three time slices viz. 2010-2039, 2040-2069 and 2070-2098. Reduction in average of total basin storage was 7\% for control climate and 36, 32 and 40\% for the aforesaid three time slices. Also significant reduction was found in annual hydropower output for the control simulations and simulations of future climate.

The potential effects of climate change on water resources and hydrology of the Columbia River Basin were studied by Payne et al. (2004) using simulations derived from PCM of U.S. DOE/NCAR. The study included three projections of climate for $21^{\text {st }}$ century derived from "business-as-usual" scenarios and compared with scenario of control climate based on 1995 static emissions. Changes in monthly temperature and precipitation from PCM model were downscaled by using statistical downscaling and downscaled output was disaggregated temporally to produce daily forcing used to drive a macro scale hydrological simulation model of Columbia River Basin at a spatial resolution of $1 / 4$ degree. A dynamic downscaling approach was also used for the comparison with statistical downscaling approach and to derive the daily forcing of hydrological model for 20 year subset of PCM control climate for the period 1995-2015 and from three "Business-asusual" projections of climate for period 2040-2060. PCM scenario results derived after statistical downscaling were assessed for three time slices (2010-2039, 2040-2069 and 2070-2098) in which annual average temperature changes were $+0.5,+1.3$ and $+2.1^{\circ} \mathrm{C}$ respectively. On the other hand changes in critical precipitation of winter were $-3,+5$ and +1 percent for three time slices respectively. For RCM, simulated 
temperature change for the period $2040-2060$ was $+1.2^{\circ} \mathrm{C}$ while change in average winter precipitation was $3 \%$ as compared to RCM control climate. From the study it was found that there will be shifting of summer stream flow to winter because of temperature and precipitation changes in winter, causing reduction in snow accumulation. Also the effect of climate change was resulted into increased competition for reservoir storage among in stream flow targets and firm hydropower.

The wide range of climate change impacts corresponding to high and low scenarios in U.S. Midwest were studied by Wuebbles and Hayhoe (2004). The historical data of maximum and minimum daily temperatures along with the daily precipitation data of 300 stations of U. S. Midwest dating back over a century was collected from Midwestern Regional Climate Centre located in Illinois State Water Survey. A1F1, A2, B1, B2 scenarios were used to force the GCM like HadCM3 model while scenarios A2 and B2 were used to force the PCM. Projected future change was calibrated with historical record of period 1961-1990 as reference. The effect of climate change on water resources will be reduction in the levels of lake with preponing of maximum levels and lowering of magnitude of maximum levels than normally observed. Warmer temperatures in winter were found to decrease ice cover length, extent and subsequently increased evaporation due to increased open water area. Runoff reduction and increased irrigation could devastate the Illinois and other Midwestern state streams. Flooding of rivers because of intense storms will encourage erosion and additional lake and wetland pollution, may be with more frequency due to drier soils and urbanization.

Annual and dry-wet season time series of eight climate variables were assessed by Rodriguez da Silva (2004) for verifying existence of variability of climate in the Northeast Brazil. The eight climate variables considered were daily maximum, minimum and average air temperatures, relative air humidity, reference evapotranspiration, class A pan evaporation, aridity index and totals of annual rainfall. Trends of the climatic variables were found out by Mann-Kendall test. Increasing trends were found for most of the variables by using Mann-Kendall test however the trends of relative humidity and rainfall were found to be decreasing. The study shown that majority of the stations studied were going through the environmental dryness process. Study also revealed that the historical trends may be related to variability of climate in Northeast of Brazil affecting semiarid and coastal area of region.

The potential impacts of climate change on the assessments of capabilities of water supply and incorporation of climate change in Water Availability Modeling (WAM) system were investigated in the study by Wurbs et al. (2005). WAM was a tool to support the planning activities and regulatory activities. The river basin hydrology of the study area was incorporated in to the WAM system through historical monthly naturalized streamflow along with the rates of net reservoir evaporation. Canadian Centre for Climate Modeling (CCCMA) climate model along with Soil and Water Assessment Tool (SWAT) watershed hydrology model were used to adjust the hydrology of WAM system to represent the anomalous climate during period 20402060. The climate model was forced by the scenario IS92a. A novel modeling approach was used in the study for exploring the effects of climate change on water availability at hydrological and institutional level for numerous water users who rely on Brazos River Basin for water supply. Analysis of historical naturalized streamflow had shown presence of crucial but hidden multiyear cycles but absence of long term trends during $20^{\text {th }}$ century. The future climate scenarios have shown decrease in the mean streamflows and greater variability. However the effects on the availability of water were varying significantly in different regions and among water users in study area.

Effect of climate change at regional scale on the important climate hydrological, biophysical indicators across the North East U.S.A. was studied by Hayhoe et al. (2006). Nine Atmosphere Ocean General Circulation Models (AOGCMs) available in the database of IPCC AR4 WG1 were used in the study. Climate models were forced with scenarios of "Twentieth Century Climate in Coupled Models" (20C3M scenarios) for historical simulations for the period 1900-1999 and A1FI, mid high (A2) along with lower (B1) emission scenarios were used for future simulations for the period (2000-2099). Statistically downscaled simulations of monthly temperature and precipitation from climate models were used as input for hydrological model "VIC" to estimate the runoff, soil moisture and evapotranspiration and snow water equivalent. The temperature 
change related indicators like seasonal pattern of warming, high spring stream flow advances, snow depth reduction, extended seasons of growing and earlier bloom dates were reproduced by the simulations of model for past and projected to continue in future. Also other indicators have shown that projected changes in future were consistent with warmer climate.

Study by Plummer et al. (2006) presented analysis of multi decadal climate simulations of present (19711990) and future (2041-2060) derived from the Canadian Regional Climate Model (CRCM). Effects of model domain size and general circulation model internal variability on CRCM were used to provide the necessary boundary conditions and physical parameterization modifications. The scenarios used were IS92a and A2. The simulations driven by output from general circulation model have shown significant warm bias for surface air temperatures in wintertime at the Northern regions of America. Model summer time precipitation was higher than the observed. This bias was present in both simulations driven by GCM and driven by reanalysis. Alterations in seasonal average precipitation were found in the range of $\pm 10 \%$ of amounts of present day for most seasons and regions.

The integrated model, dynamically describing the relationships between the forcing of climate, availability of water, agriculture and selected processes of society was used by Krol and Bronstert (2007) to study sensitivity of socio-economy and regional natural resources to climate change in semi-arid Northeast Brazil. The regional integrated model used in the study was Semi-arid Integrated Model (SIM). Climate forcings were given as input to the SIM which consisted of historic reconstruction data and scenario of climate change. The historic reconstruction was consisting of time series of precipitation and temperature at daily time scale and municipal resolution for time period 1921-1998 while climate scenarios were derived from statistical scenario technique (STAR). From the study it was found that the river flow, storage of water and production from the irrigated land were the specifically affected sectors under the scenario of continuous regional development and plausible alterations in climate. It was found that river flow, water storage and irrigated production will be stressed under the scenario of plausible favorable alterations in climate.

Historical trends of precipitation, stream flow and temperature for seventy years at the Great Lakes of North America were derived from Mann-Kendall statistics and long term regression analysis by McBean and Mottie (2008). The Great Lakes of North America are Lake Superior, Michigan, Huron, Erie and Ontario. Results derived from two statistical methods have shown significant increase in the precipitation, temperature and stream flow in study area over seven decade period. Also projected trends from historical data were found to be higher than that of using predictions of GCM for Lake Michigan/Huron. Streamflow trend lines at three rivers of St. Clair, St. Lawrence, Niagara and levels of precipitation at four out of five Great Lakes shown increase in streamflow and precipitation at statistically significant levels. Similarity of extrapolated projections from historical trends and that of from GCMs was the evidence of impact of climate change on hydrological parameter like precipitation in the basin of Great Lakes.

The study by Pike et al. (2008) presented recent climate changes which have occurred in British Columbia. The expected changes in response to climate change were: increased risks of droughts, landslides, floods and these will result in to significant changes in socio-economic, physical and biological sectors. So to carry out adaptations and mitigations in some cases to respond climate change, the information about hydrological implications for future is required. So, effect of climate change in terms of eight broad implications related to hydrology was presented. These implications were: increased demand of atmospheric evaporation, changed vegetation composition, increased temperatures of stream/lake, increased frequency/magnitude of storms and disturbances, decreased snow cover and increase in snowmelt runoff, rapid melting of permafrost and lake ice along with river ice, adjustments in glacier mass balance, altered stream flow magnitudes and timings. Study shown that accompanying alterations and associated implications for hydrology will affect the agriculture, forestry, fishery, recreation, hydropower and water resources of British Columbia. The projected effects of climate change on streamflow were found to differ across the province. So, local strategies of adaptation and mitigation were found to be needed. 
Barnett and Pierce (2009) explored sustainability of the currently scheduled future deliveries of water from Colorado River system under various scenarios of climate change. The study extended those studies which estimated multiple time series of probabilities of water deliveries and shortages in water deliveries from Colorado River in future. The simple water budget model "Colorado River Budget Model" (CRBM) was used to found the net effect of monthly inflows and outflows. The study had shown that for scenario of climate change corresponding to runoff reduction by $10 \%$, scheduled deliveries were found to be missed for $\approx 58 \%$ of the time by the year 2050. If runoff reduced by $20 \%$ then it was found that scheduled deliveries will be missed for $\approx 88 \%$ of the time. From the study it was found that the currently scheduled future deliveries of water from Colorado River were not sustainable under the scenario of climate change or mean flows of long time. It was shown that the system ability to mitigate the droughts could be maintained if various users reduce their average deliveries.

\section{Summary of case studies from America continent}

In America continent, majority of case studies were from U.S.A. and some from other countries like Brazil, Canada. Some studies assessed effect of climate change through chain of GCM-downscaling-rainfallhydrologic model-runoff while few assessed climate change impact through trend studies. Mostly GCMs and scenarios of IPCC were used. Most commonly used GCMs were GFDL, Canadian General Circulation Model 2 (CGCM2), Canadian General Circulation Model 3(CGCM3), PCM, Hadley Centre Model 2 (HadCM2), HadCM3. Also hypothetical scenarios like increase in temperature and increase or decrease in precipitation were also used in the studies. Different types of hydrological models were used in the study like VIC Model, models based on system dynamics etc. Many studies have not used downscaling techniques while few studies have used dynamic downscaling and very few studies used statistical downscaling techniques. The climate change impact was different for various scenarios. Many studies have shown increase in winter runoff and decrease in summer runoff. Overall systematic approach of assessing the impact of climate change by using all IPCC GCMs appropriate for given study area, scenarios, downscaling methods, hydrological models appropriate for given study area and ensemble averaging techniques was absent in the study.

\section{Studies from Europe Continent}

The study of effect of climate change corresponding to climate scenarios derived from two methods based on changes in runoff of ten drainage basins located in England and Wales was carried out by Palutikof (1987). First method was consisting of comparison of reconstructed data of river flow of warmest and coldest periods of twenty year of $20^{\text {th }}$ century. The second method included direct impacts of $\mathrm{CO}_{2}$ on transpiration process of plant into the analysis. The first method shown reduction in river flow in Southern England and Wales while increase in Northern region. On the other hand second method had shown that the river flow was expected to increase across the country.

Sensitivity of reservoir water storage and hydropower production to variability of climate and regional basis change was analyzed in the study by Mimikou et al. (1991). The study was the second among the two papers describing the climate change effects on hydrology at regional scale. With a set of plausible hypothetical scenarios of climate presenting greenhouse warming and changes in precipitation, sensitivity of annual guaranteed fresh water supply and guaranteed levels of energy supply were evaluated for context of runoff change for four linked multipurpose reservoirs located in the Central Greece. The two scenarios were used for the study. The first scenario was derived by superimposing conditions of $-20 \%,-10 \%, 0 \%,+10 \%$ and $+20 \%$ changes on monthly time series of precipitation having length of 16 years and occurred in past. The second scenario was derived from superimposing the conditions of $+1{ }^{\circ} \mathrm{C},+2^{\circ} \mathrm{C},+4^{0} \mathrm{C}$ increase in the 16 year monthly temperature time series of past. For each of these 15 pairs of scenarios of temperature and precipitation, climatically affected 15 monthly runoff time series were generated and given as inputs to reservoirs at each basin outlet for assessing the sensitivity to expected changes in climate. The results of the study shown dramatic increase in the risks related with annual guaranteed water supply quantity and annual guaranteed production of energy for the scenario of climate change corresponding to decrease in annual precipitation. 
Thus for maintaining existing energy and water yields at tolerable levels of risk, need of significant increase of storage was suggested.

Kwadijk and Rotmans (1995) studied the effect of climate change on the flow of Rhine River with the help of climate assessment model 'ESCAPE' coupled with water balance model 'RHINEFLOW'. The water balance model was validated on the dataset of period November 1956-October 1980. The changes in annual water availability of the region and seasonal discharge of Rhine River Basin were estimated for climate change scenarios like "Business as Usual" scenarios and accelerated policies scenarios. 'Best guess' was made for changes in seasonal discharge, changes in low and high discharge frequencies in downstream reaches of the Rhine River with quantitative uncertainty estimation. The uncertainty of business as usual scenarios was found to be 2 to 3 times of that of accelerated policies scenarios because of doubtful simulations of precipitation by general circulation models. 'Best guess' changes in annual availability of water were found to be small for both scenarios. Also study shown conversion of Rhine River from snow-melt-rainfed river to almost rainfed river. The difference between observed large average discharge of winter and autumn small average discharge was found to increase for all scenarios. The reduction in summer discharge was also simulated in the study. So, 'best guess' scenarios have shown increase in the frequencies of low and high flow events in the downstream portion of the river.

Effect of El Nino and droughts associated with it affect the freshwater resources of islands in the region of tropical Pacific. Low lying atoll areas were found to be vulnerable to these droughts because of their dependence on the rainwater as source of fresh water. Kapingamarangi atoll area of tropical pacific region was taken as case study. A global coupled GCM of second generation evolved at National Centre for Atmospheric Research was integrated for the period of 75 years for the scenario of increasing atmospheric $\mathrm{CO}_{2}$ at the rate of yearly $1 \%$ compounded. Last 20 years of this simulation experiment were analyzed and compared with the control integration with existing $\mathrm{CO}_{2}$ amounts. Significant increases in precipitation of central equatorial Pacific were found to be accompanied by the reduced precipitation in northern and southern tropical Pacific and similar changes were observed in Australasian region and regions of eastern Indian Ocean. So, future increased drought conditions in certain regions of tropical Pacific as shown by the simulations of climate model could limit the sustainability of population in atoll regions and so, probable migration and increased urbanization of atoll population to larger high island areas may happen where sufficient amount of water will be available to fulfill their needs (Meehl, 1996).

Effect of climate change on the Europe continent by 2050s were assessed by Arnell (1999) at spatial resolution of $0.5^{0} \times 0.5^{0}$ latitude / longitude. The hydrological regimes were simulated by the application of daily time step macro scale hydrological model and four scenarios of climate change. Four scenarios used were UKHI (UK Hadley Centre), UKTR (UK Hadley Centre), CCC (Canadian Climate Centre) and GHGx (UK Hadley Centre). All four scenarios have shown decrease in annual runoff in the region of southern Europe and increase in northern Europe. In maritime areas the range of runoff throughout the year was found to be increased with low flows in summer although change in the timings of the flow was small. Study shown increase in the winter runoff with reduction in spring runoff across the large region of the eastern Europe. Further study had shown that drought intensity will increase in most of the western Europe and will reduce in north and east Europe.

Potential impacts of climate change on the water resources of the Auckland region of New Zealand was assessed by Fowler (1999) using future climate change scenarios and a daily water balance model to convert the scenarios in to seasonal impacts on the regime of soil water and catchment water yield. The three future time slices considered for the study were 2020, 2050 and 2100. The two sites in the Aukland considered for the study were Auckland airport and Pukekohe. Scenarios of climate change like IS92a, IS92e, IS92c were obtained in the form of envelopes and best guesses with known quantifiable sources of uncertainty at regional and global scales. Water balance model was run for historical precipitation and potential evaporation time series of two selected sites indicating regional differences in regimes of climate. Simulations were carried out for variety of site characteristics like vegetation, capacity of soil water storage, soil drainage by performing appropriate adjustments to parameters of model. Impact assessments of seasonal summary variables nested 
within more general sensitivity analysis deduced from multiple simulation runs of water balance model were performed by allowing systematic changes to input variables. Scenario overlay given an insight of the potential climate change impacts on the mean conditions while frequency analysis was focused on the changes in the level of 5 year return period which is considered to be significant for water resources planning. A key result from the analysis of soil water regime was uncertainty in the direction of impacts for all scenarios, regimes of climate, seasons and characteristics of site. So, best guess was negligible change in climate.

Jose and Cruz (1999) carried out a preliminary and limited evaluation of impact of climate change on Philippines water resources by using GCM results and scenarios of climate change incorporating incremental changes in rainfall, temperature and application of hydrologic model WatBal for simulating rainfall-runoff relationships in future. The GCMs used were Canadian Climate Centre Model (CCCM), United Kingdom Meteorological Model (UKMO) and GFDL Model. Incremental change scenarios used were T2P10, T4P10. The results shown that the alterations in the future rainfall and temperature would be critical to corresponding inflow in Angat reservoir and Lake Lanao with variability of rainfall having dominant effect compared to variability of temperature. Lake Lanao was expected to have reduction in future runoff. Possible ways for coping with future water resources problems of study area were suggested.

$\mathrm{Xu}$ (2000) investigated the impacts of climate change on the regimes of flow in twenty five catchments located in Central Sweden. Hydrological responses corresponding to 15 scenarios of hypothetical climate change like combination of scenarios of $\Delta \mathrm{t}=+1,+2$ and $+4^{\circ} \mathrm{C}$ and $\Delta \mathrm{P}=0, \pm 10 \%, \pm 20 \%$ were simulated by application of conceptual water balance model at monthly time scale. The results have shown that all scenarios of hypothetical climate change will cause major reduction in accumulation of winter snow. Attendant increase in winter flow and reduction in spring and summer runoff were observed for most of scenarios. Significant changes in the actual evapotranspiration magnitude were also observed for all scenarios of climate change. Annual total evapotranspiration change was found to be small with maximum change of $23 \%$ against $76 \%$ change in the value of mean annual snow water equivalent and $52 \%$ change in the value of mean annual runoff.

Chang et al. (2002) examined regional climate change impacts on runoff in mountainous areas of southwestern Bulgaria. A geographical information system based distributed hydrological model and two scenarios of climate change obtained from HadCM2 and Canadian Centre for Climate Modeling and Research (CCC) were used for simulating runoff of years around 2025 and 2085. Result of the study illustrated the sensitivity of the basin's runoff to climate change scenario corresponding to generation of attendant changes in water yield of basin across time and space with shifting of basin's maximum runoff into early spring and further reduction in summer runoff. Increased spatial variation of runoff was found because of complex physiography of the basin. Reduction in mean annual runoff was not found only for the Hadley scenario by 2085. Also association was found between mean monthly and peak flow magnitude with early snowmelt and decrease in spring season snow cover.

Beldring et al. (2005) used climate scenarios A2 and B2 from HadAm3 under Regional climate project to study climate change impacts on hydrologic processes in headwater catchments of Central Norway and at the Hardangervidda plateau of South Norway. The GCM outputs were downscaled with the help of regional climate model "HIRHAM". Two models representing the land surface hydrological conditions and thermal conditions were applied in the study. These two models were HBV and COUP. COUP model was used to simulate the water and energy exchange in a vertical profile starting from the atmosphere to soil underlying through the vegetation. HBV model was used for modeling of catchment scale hydrologic processes. HBV model was used because of inability of COUP model to model land surface hydrology at greater spatial scales. HBV model was sensitive to the variations in the land surface properties and input climate data. The study had shown moderate changes in the annual streamflow although changes in seasonal streamflow were larger. Values of annual mean storage of snow, frozen ground depth and ground water table depth were projected to decrease. 
The study of effect of climate change on the storm surges often responsible for flooding of coastal areas of United Kingdom was carried out by Lowe and Gregory (2005). For the study, the global atmospheric model of Hadley Centre HadAM3H was applied to give input of boundary conditions to HadRM3H, a regional atmospheric model. The output of atmospheric winds and pressure provided by regional climate model was used to drive a $35 \mathrm{~km}$ model of seas of UK shelf area, availed from Proudman Oceanographic Laboratory. The study was carried out for two periods i.e. present day period (1961-1990) and future period (2071-2100) using A2 and B2 emission scenarios. Study showed agreement with earlier studies indicating changes in storminess of atmosphere and greater time average sea level towards the end of the $21^{\text {st }}$ century. Also largest increase in storm surge height was found to occur along off the southeast coast of UK.

Alcamo et al. (2007) studied the effect of varying frequency and heterogeneity in space of extreme climate events on agriculture and water resources of Russia with the help of Global Assessment of Security (GLASS) model and A2, B2 climate scenarios of IPCC. GLASS model was consisting of Global Agro Ecological Zones (GAEZ) crop production model and Water Global Assessment and Prognosis (WaterGAP2) model of water resources. Under the normal climate conditions it was found that the food production deficiency was occurring 1-3 years of each decade. Due to climate change effect frequency of food production deficiency was found to become double in 2020s and triple in 2070s in many of the major crop growing areas. Effect of the crop shortfall occurring in many main crop growing regions of Russia will get propagated throughout the Russia, as it depends on few main crop growing areas for its food demand. The study of climate impacts on water resources had shown increased average water availability in Russia with raised frequency of events of high runoff in most parts of central Russia. Also more frequent events of low runoff were projected in dry crop growing regions of south part of Russia. The study indicated increased threat to security of agriculture and water resources of Russia from increased frequencies of extreme climate events.

By application of UKCIP02 Medium High Climate Scenario for the period 2070-2100, the effect of climate change on integrated resource zone (IRZ) operation was studied by Fowler et al. (2007). HadRM3H regional climate model (RCM) developed at Hadley Centre of UK meteorological office and MOSPA water resources model was used for the study. Boundary conditions for the regional climate model were deduced from HadAM3H global atmosphere model. The IRZ was system of complex conjunctive use water supply of north west England. An ensemble of three integrations was run for the baseline period of 1960-1990 by using sea surface temperature (SST) and sea ice observations. Similarly ensemble of three integrations was also produced for future period of 2070-2100 using UKCIP02 scenario and alterations in SST and sea ice simulated by HadCM3 added in observations. Blaney Criddle method was used for the estimation of potential evapotranspiration for the control scenario and future scenarios. The results of the study indicated that the reduction in overall yield in the study area was about $18 \%$. The flexibility of the system was allowing to meet modeled water supply demands for the scenario of future climate change. Significant expenditure requirement was found to be needed for pumping additional abstractions from bore holes and lakes to withstand against the effect of climate change on water supply system in the north west England.

Rani et al. (2008) performed preliminary analysis of climate change impacts on Alentejo region water resources system located in the South of Portugal. Regional climate model HadRM3P was nested in and forced by GCM HadAM3P. The scenario used for forcing was A2 scenario. The data of precipitation and temperature obtained from the regional climate model was given as input to the hydrological model "System Hydrologique Europen Transport" (SHETRAN) for the simulation of streamflow in future. Models based on dynamic programming were used for reservoir system operation for assessing the climate change impact. Results were derived for both observed historical and future streamflow series for analyzing the system operation performance for the scenario of climate change. The comparison of data of control period (19611990) and climate model data (2071-2100) showed 30\% reduction in average annual precipitation and increase in average temperature by $3.7^{\circ} \mathrm{C}$. The results of the study have shown that the reservoir performance would be considerably influenced by the losses due to evaporation, which would be greater in warmer climate. So, study concluded that building storages in the reservoirs will not be beneficial. 


\section{Summary of case studies from Europe continent}

In Europe continent, many case studies were from U.K. and from other European countries like Greece, Bulgaria, Philippines, Russia and Sweden etc. Few studies assessed effect of climate change through the chain of GCM-dynamic downscaling-rainfall-hydrologic model-runoff and use of synthetic scenarios with water balance models. No study assessed climate change impact through trend detection. Mostly GCMs and scenarios of IPCC were used. Most commonly used GCMs were HadAM3H, HadRM3H, HadAM3P, HadCM2 and HadRM3P. Also hypothetical scenarios like increase in temperature and increase or decrease in precipitation were also used in the studies. Different types of hydrological models were used in the study like water balance models, distributed hydrological model etc. Many studies have not used downscaling techniques while few studies have used dynamic downscaling. The climate change impact was different for different scenarios. Many studies indicated increase in winter runoff and decrease in summer runoff. Arnell (1999) found that drought intensity will increase in Western Europe and decrease in North and East Europe. Overall systematic approach of assessing the impact of climate change by using all IPCC GCMs appropriate for given study area, scenarios, downscaling methods, hydrological models appropriate for given study area and ensemble averaging techniques was absent in the study.

\section{Asia, Africa, Australia Continent and International Case Studies}

The climate change impact on water resources of South Taiwan was studied by Yu et al. (2002). The study area chosen was a catchment upstream of Shin-Fa Bridge station in the basin of Kao-Pen Creek. The trends in historical meteorological variables like average daily temperature, wet days mean daily precipitation and wet days of each month were studied. Along with it transition probabilities of occurrence of daily precipitation events in each month at the meteorological station of Kao-Hsiung were studied using Mann-Kendall non parametric statistical test. The trends of historical meteorological variables were then used for the generation of future runoff in the study area by the application of continuous rainfall runoff model. Weather generating approach was used for extrapolating conditions of future climate using long term historical tendencies of aforesaid meteorological variables. The results of the study indicated that effect of transition probabilities of occurrence of daily precipitation was significant on the generation of precipitation in future and subsequent runoff for future conditions of climate in Southern Taiwan. The study indicated rise in the runoff in the wet season while reduction in dry season.

Study by Zeid and El-Fadel (2002), characterized water resources of several countries of Middle East and evaluated predictions of regional climate for various scenarios by application of general circulation models. Case study of country of Lebanon was considered for the in-depth assessment with potential effects on soil moisture and water budget as indicators of water resources. The WATBAL model was applied at two locations of Lebanon i.e. Ksara, in the Bekaa and coast of Mediterranean nearer to Beirut, for four different climate scenarios. First two scenarios were simulating varying increases in temperature along with stable precipitation and other two scenarios were used for reexamining the effect of same temperature increases along with $0.1 \mathrm{~mm} /$ day decrease in precipitation. Results of the study have shown that the evaporation at Beirut and Ksara will increase for all scenarios. Also the soil moisture deficit was found to increase in Beirut for the scenario of changing climate. The irrigation demand of agricultural areas was found to be correlated with the soil moisture deficit. Also it was found that the Ksara will be more affected compared to the Beirut. Study found that potential impacts may be significantly exacerbated by changes in flow regimes of snowmelt fed Lebanese rivers. So, Lebanese rivers will have increased winter streamflow and decreased streamflow in spring because of higher temperatures and earlier snowmelt leading to drier soils at the commencement of summer. Study was having some limitations like large uncertainties and discrepancies among different GCMs, lack of basin characteristics data, lack of data of accurate water balance, non inclusion of alterations in vegetation, soils and water use efficiency of vegetation in water balance model.

The effects of climate change on water cycle of agriculture and their implication for agricultural productivity in 2020s were examined by Tao et al. (2003) using calculations of water balance for croplands of China. 
Temporal and spatial variations in actual and potential evapotranspiration, soil moisture with its deficit, yield index and surface runoff from croplands were mapped for baseline climate and climate change scenario derived from HadCM2 GCM, on the resolution of $0.5^{0}$ latitude/longitude grid. The scenarios of climate change for the period 2021-2030 were derived from data of CRU mean monthly climatology and scenarios of climate change derived from GCM. From the study it was found that demand of agricultural water in South China and deficit of soil moisture in croplands was found to decrease while increase in that of in the north China. Alterations in the water resources were found to have consequent effects on the yield index. The increase in surface runoff of croplands was found in growing period at some sloping croplands located in mountain areas of southwest and in some areas situated along south coast. Also it was found that the northeast China and north China plain will confront water related challenges in decades to come because of expected increase in demands of water, soil moisture deficit and reduction in precipitation.

The relationship between climate change and water resources variability in the basin of Tarim River located in West China was investigated by Xu et al. (2004). The long term trends in the time series of hydrological variables like precipitation, temperature and streamflow were detected by application of parametric and nonparametric techniques. Non parametric techniques such as Mann-Kendall test, Kendall's Tau, Wilcoxon test and parametric test like t-test were used in the study. The study concluded that there was statistically significant increase in the temperature during the past 50 years at $5 \%$ significance level while precipitation shown the rising trend in the past several decades. The significant jump was found in the both the time series around 1986. Although head water of Tarim River shown attendant increase in precipitation and stream flow, there was decreasing trend in the streamflow along the river mainstream. So, it had clearly shown the effect of anthropogenic activities on the cessation of streamflow and drying up process of the river, instead of climate change. Study had also shown that there was no significant relationship between the ENSO and precipitation, stream flow and temperature in the study region. Study concluded that curtailment of water, desiccation of river and ecosystem deterioration of Tarim River Basin may be predominantly because of the effect of human activities.

Effect of climate change and degradation of soil on future water resources of China was studied by using a simple water balance model along with the updated database by Tao et al. (2005). Spatial pattern of alterations in the actual and potential evapotranspiration, deficits of soil moisture, surface runoff throughout the China in 2020s were plotted at the resolution of $0.5^{0} \times 0.5^{0}$ latitude and longitude for the scenarios of degradation of soil and climate change or combination of both. The simulated changes in climatology were derived by applying combination of GCM simulations and mean monthly climatological data of Climate Research Unit (CRU). The GCM used was Hadley Centre Climate model HadCM2 with integration of impacts of greenhouse gases along with sulfates and compound increase by $1 \%$. Result of the study had shown that magnitude and pattern in space of water resources on national scale were affected by climate change. Some regions of central, northeastern and southeastern China were found to become more vulnerable to disasters such as floods and droughts because of soil degradation. Under the combined effect of climate change and degradation of soil, the soil moisture deficit was found to increase most in western, central and southwestern China. Also most increase was found in the surface runoff of the southeastern China. Study concluded that more elaborative process based models were needed for capturing the feedback mechanisms more effectively.

Gosain et al. (2006) studied the effect of climate change on water resources systems of Indian rivers as component of National Communication Project taken in charge by Ministry of Environment and Forests of Government of India. The study used data of HadRM2 daily weather along with SWAT model. Simulations were performed for 20 years of control and 20 years for scenarios of future climate. For the future climate, GHG climate scenarios representing period of 2041-2060 were used. The impact was assessed for the 12 main Indian river basins but study was focused on the elaborative analyses of Krishna and Mahanadi River Basins which were found to be worst impacted. From the results of the study it was found that Krishna River Basin will undergo conditions of severe draught for GHG scenario while higher level of future precipitation and evapotranspiration along with increase in future water yield was predicted for Mahanadi River Basin. Study 
also concluded that the severity of droughts and flood intensity may get deteriorated in different parts of the country. Also general decrease in the available runoff quantity was predicted for the scenario of GHG.

Effects of climate change on the wet season paddy irrigation requirement of the Sri Lanka was studied by De Silva et al. (2007) for the 2050s with the help of UK Hadley Centre for Climate Prediction and Research Model (HadCM3) for scenarios A2 and B2 taken from the IPCC Special Emission Scenario Report. Water balance modeling along with geographical information systems were applied to model and map effects on requirement of irrigation for wet season paddy. The result of the study had shown that the average rainfall in wet season will reduce by $17 \%$ for $\mathrm{A} 2$ scenario and $9 \%$ for $\mathrm{B} 2$ scenario with preponing of rainfall and increase in potential evapotranspiration by $3.5 \%$ for $\mathrm{A} 2$ scenario and $3 \%$ for B2 scenario. Consequently the requirement of average paddy irrigation water was found to increase by $23 \%$ for A2 scenario and $13 \%$ for B2 scenario. Also study shown positive effect of climate change on wet season paddy production in extreme southern portion of Sri Lanka which was similar to the results of earlier study.

Zeng et al. (2008) reviewed challenges in front of China because of climate change. The adverse impact of climate change on China stated in the study was inundation of $92000 \mathrm{~km}^{2}$ area in the three major industrial centers of China located in low land areas viz. Gulf of Bohai region, the delta of Yangtze River radiating inland from Shanghai and delta of Pearl River. It was stated that the $21 \%$ of the mountain glaciers of northwestern China were melted during past 50 years of study. Also Tibet region temperature was found to increase by $3^{0}-6^{0} \mathrm{C}$ by 2100 . Melting of permafrost was found to cause damage to Qinghai Tibet Railway. Asian rivers like Ganges, Mekong originating from the plateau of Tibet, so alterations in water resources may cause tension with the nearby countries. Also it was found that summer storms which move eastward along the river systems will dump greater amounts of rainfall resulting into severe floods. The extreme event amplification in south and east China was also stated. Overall, study stated that maintaining green house gases at manageable levels while keeping economic development intact was found to be one of the toughest challenges in front of China in $21^{\text {st }}$ century.

The effect of climate change on water resources of Iran was studied by Abbaspour et al. (2009) with the help of hydrologic model, Canadian Global Coupled Model (CGCM 3.1) and scenarios A1B, B1 and A2. The hydrological model was calibrated for the time period of 1980-2002 by the application of daily river discharges and data of annual wheat yield at sub-basin level. Precipitation was downscaled by simple ratio method. For downscaling temperature fourth degree regression model was used. The scenarios from GCM were downscaled for the 37 climate stations throughout the country. The downscaled outputs were used to drive the hydrological model created using SWAT. Future scenarios of climate were generated for the period 2010-2040 and 2070-2100. Afterwards the hydrological model was applied for future periods to assess the future climate effect on precipitation, green water, blue water and wheat yield across the country. From the study it was found that the wet regions of Iran will have more future rainfall and dry regions will have less rainfall in future. Also daily rainfall intensity analysis indicated more frequent and higher intensity floods in wet areas while more frequent prolonged droughts in dry areas. When the variations in the predictions of three future scenarios were aggregated at the provincial levels, these variations were smaller compared to hydrological model uncertainty. However in dry regions of the Iran, the three scenarios of climate generated quite different results at sub-basin level. On the other hand results were more or less same in wet regions. It was found that, higher precipitation in the north and west parts of Iran may lead to water sources contamination risk due to sewage overflows, runoff from agricultural and urban areas along with increased sediment load and non point source loadings of pollutant into water courses. On the other side prolonged droughts may cause smaller river discharges and decrease in reservoir levels, leading to deterioration of water quality because of greater concentrations of contaminants and nutrients. Increase in temperatures of water may lead to increased algae growth and consequent reduction in concentrations of dissolved oxygen.

Study by Immerzeel et al. (2010) used the Normalized Melt Index for finding the significance of upstream area meltwater on overall basin hydrology for the period 2001-2007. The study used Snowmelt Runoff Model (SRM) which was forced by outputs derived from five GCMs for the scenario of SRES A1B for the period 2046-2065 along with two additional scenarios of future size of glacier. Study has also made a review of 
articles related to effect of climate change on ice volumes of Asian basins. The review had shown general decreasing trend of volumes of ice in Asian basins. The melt water from ice cover and snow were expected to get affected by alterations in temperature and precipitation. Study had shown that the Indus and Brahmaputra Basins were largely influenced by the melt water and influence of melt water on Ganges, Yangtze and Yellow Rivers was found to be modest. The effect of climate change was found to have huge difference among the basins to affect availability of water and food security. Indus and Brahmaputra Basins were found to be the most susceptible to decrease in flows thereby threatening the security of food of 60 million peoples. Indus and Brahmaputra River Basins were also shown consistent trends of decreasing late spring and summer discharges around the period 2046 to 2065.

Assessment of climate change effect on water resources with suggestions of appropriate adaptation measures was performed by Tarekegn and Tadege for the Lake Tana sub-basin of Ethiopia. The runoff vulnerability corresponding to climate change in Lake Tana sub-basin was evaluated by using hydrological water balance model WatBal. WatBal needs meteorological and hydrological data as input such as rainfall, relative humidity, temperature, sunshine hours and data of monthly flow etc. at the outlet of sub-basin. Scenarios used in the study were synthetic scenarios and GCM derived scenarios. Synthetic scenarios used for the study were: rise in temperature by $2^{\circ} \mathrm{C}$ and $4^{\circ} \mathrm{C}$ and variations in the rainfall amount by $-20 \%,-10 \%, 0 \%,+20 \%$, $+10 \%$. GCM derived scenarios were derived from the output of three GCMs namely CCCM, GFD3, UK89 and condition of doubled $\mathrm{Co}_{2}$. From the study it was revealed that due to climate change the seasonality of streamflow will increase, resulting in to drying up of small streams completely for part of the year. This variation in runoff will affect the socio-economic scenario of the sub-basin because of rainfed agriculture and use of mostly springs and small streams for rural water supply.

The study by New (2002) focused on the effect of different changes in future climate on the sensitivity of runoff for next 50 years in four mountainous catchments of southwestern cape of South Africa by using GCM predictions for future climate. The response system sensitivity to wide range of possible changes in climate enabled determination of threshold of response system and identification of significant climate change. Sensitivity of projected streamflows to various arbitrary adjustments made to precipitation and potential evapotranspiration as scenarios was assessed through the hydrological model ACRU. ACRU was a physicalconceptual model simulating rainfall runoff relationship. ACRU was simulating base flows and storm flows separately with improvement enabling the throughflow simulation. The most likely response of streamflow was considered in terms of capacity of current and projected future water resource supplies with demand of the Cape Metropolitan Region. The most likely stream flow responses were obtained from combination of simulated streamflow of catchments with recent GCM projections of climate change for the 2050s. From the study, projected supply capacity was found to decrease non-linearly with reduction in precipitation and increase in potential evapotranspiration which were most likely scenarios of predicted alterations of the regional climate. More arid catchments have shown greater sensitivity to these changes. On average most probable variation in capacity of water supply of CMR was found to be $0.32 \%$ reduction per annum upto 2020. Due to climate change the increase in demand of water was found to be $0.6 \%$ per year which would be superimposed on increases in other demand. By using the current development plans of water resources it was found to be difficult to fulfill 1:50 year supply yield of CMR because of increased demand and predicted decrease in water supply. Also the greater consequences of failure of water supply were found as compared to expected.

Jones and Page (2001) analyzed risk of climate change by using water resources modelling results of the catchment of Macquarie River in New South Wales (NSW) of Australia. Study used climate change scenarios obtained from the nine global climate models outputs. These scenarios of climate change for 2030 and 2070 were applied to perturb a historic daily climate of rainfall of long term $(\mathrm{P})$ and potential evaporation $\left(\mathrm{E}_{\mathrm{p}}\right)$. OzClim, CSIRO's climate scenario generator was coupled with Integrated Quality Quantity Model (IQQM) of the Macquarie River evolved by department of Land and Water Conservation of NSW. The relationships of $\delta \mathrm{P}, \delta \mathrm{E}_{\mathrm{p}}$ with water storage, environmental flows of Macquarie Marsh and irrigation allocations were determined and probability distribution functions (PDFs) of environmental flows and irrigation allocations were constructed by using Monte Carlo Sampling. Critical thresholds for the environmental flows and 
irrigation allocations were determined. Decadal variability impacting the rainfall was found to differ with results of base line by $\pm 20 \%$ from the mean of long term. These critical thresholds were found to exceed if reduction of streamflow with respect to the long term mean was greater than $10 \%$ for climate of drought dominance, greater than $20 \%$ for normal climate and greater than $30 \%$ for the flood dominated climate. The uncertainty analysis shown that the uncertainty due to global warming was $25 \%$ of total climate change uncertainty, uncertainty due to rainfall change was $64 \%$ of total climate change uncertainty while uncertainty due to potential evaporation changes was found to be $12 \%$ of total climate change uncertainty. Although the Bayesian analysis shown that threshold exceedance risk will vary by small amount due to change in input assumptions of rainfall or global warming which either expand uncertainty or change its prior distribution. The most likely changes in mean annual storage of Burrendong Dam, inflows of Macquarie Marsh and irrigation allocations were $0 \%$ to $-15 \%$ in year 2030 and $0 \%$ to $-35 \%$ in year 2070 . Probability of increase of flows was found to be $5 \%$ in 2030 and 2070 for most assumptions. Also it was found that for drought dominated regime of rainfall in 2030, the critical threshold exceedance risk was $20-30 \%$ of climates. This risk was reduced to $<1 \%$ for normal climate and $<<1 \%$ for climate of flood dominance. In 2070 , these exceedance risks were found to be $70-80 \%, 35-50 \%$ and $10-20 \%$.

Beare and Heaney (2002) applied a simulation model to study the potential effects of variations in precipitation and evaporation corresponding to two climate change scenarios developed by IPCC in Murray Darling Basin of Australia. Simulation model used was Salinity and Land Use Simulation Analysis (SALSA) model. Simulation model was developed at Australian Bureau of Agricultural and Resource Economics (ABARE) with the cooperation of Murray Darling Basin Commission and Land and Water Division of CSIRO. The SALSA model was incorporating the relationships among the land use, vegetation cover, ground and surface water hydrology and returns from agriculture. For four SRES scenarios considered in the study, the expected changes were: decrease in the precipitation and increase in the evaporation over most of the Murray Darling Basin in $21^{\text {st }}$ century. The consequent decrease in the surface water flows over short time span combined with the delayed impacts of a decrease in recharge of ground water was found to result in positive and negative environmental and economic effects.

The study by Nicholls (1995) focused on the effect of climate change on the coastal megacities. Rapid urbanization was found to be responsible for the development of 20 coastal megacities by the year 2010. In 1990, in Asia there were seven coastal megacities except those in Japan along with two in South America, increasing to 12 in Asia consisting Istanbul with three in South America and only one in Africa by 2010. These all locations along the coast consisting megacities were found to be at risk due to increased sea levels across the world and altered frequencies of storm because of climate change. Subsidence of many coastal megacities was found for those resting on geologically young sedimentary strata which were susceptible to subsidence because of excessive withdrawal of groundwater. Minimum eight out of 20 projected coastal megacities were found to undergo experience of local rise or relative sea level rise which usually greatly exceeds any plausible scenario of global sea level rise. The effects of sea level rise on coastal megacities were found to include: increased flooding risk and impended drainage, salinization of supplies of freshwater, threat to the safety of foundations due to high water tables and beach erosion. Climate change implications on each coastal megacity were found to vary significantly. So, independent assessment of climate change effects on each coastal megacity was suggested.

Study by Rosenzweig et al. (2004) was focused on the methods of linking scenarios of climate change with the agricultural, hydrologic and planning models to assess the availability of water for agriculture, estimate alterations in services of ecosystem and to evaluate strategies of adaptation for water resources sectors and agriculture sectors. The models used were water balance model WATBAL for supply of water, SOYGRO, CERES-Maize, CROPWAT for yield of crop and irrigation demand and WEAP for forecasting of water demand, planning and evaluation. These models were applied at study area for the current conditions and set of future climate change scenarios. The models were applied at the major agricultural areas like Argentina, Brazil, Hungary, China, Romania and USA by applying projections of climate change, production from agriculture, population, technology and gross domestic product (GDP) growth. From the study it was found that majority of the relatively water rich regions will have sufficient water for agriculture under tested 
scenarios of climate change while Northeastern China shown highest lack of availability of water for agriculture and ecosystem services for current conditions and conditions of climate change projections. Substantial change was not found in the projected runoff of the Danube Basin, although the shifts were observed in environmental stresses of the region due to climate change. The Northern Argentina was found to face the exacerbation of occasional problems in agricultural water supply under the conditions of climate change, suggesting requirement of investments for relieving future tributary stress. Future agricultural water supply in Southeastern Brazil was found to be plentiful. The water supply in majority of the US Cornbelt was found to increase for most scenarios of climate change in future but with water logging in summer and tractability concern in spring. Thus study concluded with need of: timely improvements of crop cultivars, drainage and irrigation technology and management of water.

\section{Summary of case studies from Asia, Africa, Australia Continent and International Case Studies}

In Asia continent, many case studies were from China and few were from other Asian countries like India, Sri Lanka and Iran etc. Very few studies assessed effect of climate change through the chain of GCMdownscaling-rainfall-hydrologic model-runoff and use of synthetic scenarios or GCM derived scenarios with water balance models while few assessed climate change impacts through trend studies. Mostly GCMs and scenarios of IPCC were used. Most commonly used GCMs were HadCM2, HadRM2, HadCM3, CGCM 3.1 etc. Also hypothetical scenarios like increase in temperature and increase or decrease in precipitation were used. Different types of hydrological models were used in the study like water balance models, SWAT etc. Many studies have not used downscaling techniques while very few studies used crude methods like simple ratio method, statistical downscaling technique. The climate change impact was different for different scenarios. Many studies concluded increase in winter runoff and reduction in summer runoff. Overall systematic approach of assessing the impact of climate change by using all IPCC GCMs appropriate for given study area, scenarios, downscaling methods, hydrological models appropriate for given study area and ensemble averaging techniques was absent in the study. Very few international studies, case studies from Africa and Australia were available and aspects of these case studies were similar to those of Asian case studies.

\section{Conclusions}

1) The number of case studies from America, UK, China are more as compared to other countries.

2) No studies were carried out with all IPCC GCMs, scenarios, downscaling methods.

3) So, complete assessment of uncertainty is difficult and without correct assessment of uncertainty in climate impact the appropriate adaptation measures cannot be specified and carried out.

\section{References}

Abbaspour, K. C., Faramarzi, M., Ghasemi, S. S. and Yang, H. (2009), "Assessing the impact of climate change on water resources in Iran", Water Resources Research, Vol.45, W10434, 16p, Available at: doi:10.1029/2008WR007615.

Alcamo, J., Dronin, N., Endejan, M., Golubev, G. and Kirilenko, A. (2007), "A new assessment of climate change impacts on food production shortfalls and water availability in Russia", Global Environmental Change, Vol.17, pp. 429-444.

Arnell, N. W. (1999), "The effect of climate change on hydrological regimes in Europe: a continental perspective", Global Environmental Change, Vol. 9, pp. 5-23.

Askew, A. J. (1987), "Climate change and water resources", in The Influence of Climate Change and Climatic Variability on the Hydrologie Regime and Water Resources (Proceedings of the Vancouver Symposium, August 1987), IAHS Publ. No. 168, pp. 421-430.

Barnett, T., Malone, R., Pennell, W., Slammer, D., Semtner, B. and Washington, W. (2004), "Effect of climate change on water resources in the west: introduction and overview”, Climatic Change, Vol. 62, pp. 1-11. 
Barnett, T. P. and Pierce, D. W. (2009), "Sustainable water deliveries from the Colorado river in a changing climate", Proceedings of National Academy of Sciences (PNAS), Vol. 106, No. 18, pp. 7334-7338, Available at: www.pnas.org_cgi_doi_10.1073_pnas.0812762106

Bates, B.C., Kundzewicz, Z.W., Wu, S. and Palutikof, J.P. (Eds.) (2008), "Climate change and water", Technical Paper of the Intergovernmental Panel on Climate Change, IPCC Secretariat, Geneva, 210 pp.

Beare, S. and Heaney, A. (2002), "Climate change and water resources in Murray Darling basin, Australia, impacts and possible adaptation", in 2002 World Congress of Environmental and Resource Economists in Monterey, California, ABARE Conference Paper 02.11.

Beldring, S., Colleuille, H., Haugen, L. E., Roald, L. A. and Overlie, T. (2005), "Climate change impacts on hydrological processes in headwater catchments", in Headwater Control IAHC Conference, Bergen, 2005, Available http://www.nve.no/Global/Vann\%20og\%20vassdrag/Effekter\%20av\%20klimaendringer/HeadWater2005.pdf

Chang, H., Knight, C. G., Staneva, M. P. and Kostov, D. (2002), "Water resource impacts of climate change in south western Bulgaria", GeoJournal, Vol. 57, pp. 159-168.

Christiansen, N. S., Wood, A. W., Voisin, N., Lettenmaier, D. P. and Palmer, R. N. (2004), "The effects of climate change on the hydrology and water resources of the Colorado river basin", Climatic Change, Vol. 62, pp. 337-363.

Collischonn, W., Tucci, C. E. M. and Clarke, R. T. (2001), "Further evidence of changes in the hydrological regime of the river Paraguay: part of wider phenomenon of climate change", Journal of Hydrology, Vol. 245, pp. 218-238.

Croley II, T. E., Quinn, F. H., Kunkel, K. E. and Changnon, C. A. (1996), “Climate transposition effects on the Great Lakes hydrological cycle", NOAA Technical Memorandum, ERL GLERL-89, Great Lakes Environmental Research Laboratory, Ann Arbor, Michigan.

De Silva, C.S., Weatherhead, E. K., Knox, J. W. and Rodriguez -Diaz, J. A. (2007), "Predicting the impacts of climate change - a case study of paddy irrigation water requirements in Sri Lanka", Agricultural Water Management, Vol. 93, pp. 19-29.

Doll, P. (2002), "Impact of climate change and variability on irrigation requirement: a global perspective", Climatic Change, Vol. 54, pp. 269-293.

Dyurgerov, M. B. and Meier, M. F. (2000), "Twentieth century climate change: evidence from small glaciers", Proceedings of the National Academy of Sciences, Vol.97, No.4, pp. 1406-1411.

Fowler, A. (1999), "Potential climate change impacts on water resources in the Aukland region (New Zealand)", Climate Research, Vol.11, pp. 221-245.

Fowler, H. J., Kilsby, C. G. and Stunell, J. (2007), "Modelling the impacts of projected future climate change on water resources in north-west England", Hydrol. Earth Syst. Sci., Vol. 11, No. 3, pp. 1115-1126.

Gleick, P. H. (1987), "Regional hydrological consequences of increases of atmospheric $\mathrm{co}_{2}$ and other trace gases", Climatic Change, Vol. 10, pp. 137-161.

Gosain, A. K., Rao, S. and Basuray, D. (2006), "Climate change impact assessment on hydrology of Indian rivers", Current Science, Vol. 90, No. 3, pp. 346-353.

Hartmann, H. C. (1990), "Climate change impacts on Laurentian Great Lakes levels", Climatic Change, Vol. 17, pp. 49-67.

Hayhoe, K., Wake, C. P., Huntington, T. G., Luo, L., Schwartz, M. D., Sheffield, J., Wood, E., Anderson, B., Bradbury, J., Degaetano, A., Troy, T. J. and Wolf, D. (2006), "Past and future changes in climate and hydrological indicators in the U.S. north east", Climate Dynamics, pp. 1-32, Available at: DOI 10.1007/s00382-006-0187-8

Hegerl, G.C., Zwiers, F. W., Braconnot, P., Gillett, N.P., Luo, Y., Marengo Orsini, J. A., Nicholls, N., Penner, J.E. and Stott, P.A. (2007), "Understanding and Attributing Climate Change", In: Climate Change 2007: The Physical Science Basis, Contribution of Working Group I to the Fourth Assessment Report of the Intergovernmental Panel on Climate Change [Solomon, S., Qin, D., Manning, M., Chen, Z., Marquis, M., Averyt, K. B., Tignor, M. and Miller, H. L. (eds.)], Cambridge University Press, Cambridge, United Kingdom and New York, NY, USA.

Immerzeel, W. W., P. H. van Beek, L. and Bierkens, M. P. F. (2010), "Climate change will affect the Asian water towers", SCIENCE, Vol. 328, pp. 1382-1385. 
IPCC (2007), "Summary for policymakers", In: Climate Change 2007: The Physical Science Basis, Contribution of Working Group I to the Fourth Assessment Report of the Intergovernmental Panel on Climate Change [Solomon, S., Qin, D., Manning, M., Chen, Z., Marquis, M., Averyt, K. B., Tignor, M. and Miller, H. L. (eds.)], Cambridge University Press, Cambridge, United Kingdom and New York, NY, USA.

Jones, R. N. and Page, C. M. (2001), "Assessing the risk of climate change on the water resources of the Macquarie river catchment", in Ghassemi, F., Whetton, P., Little, R. and Littleboy, M. (eds.), Integrating Models for Natural Resources Management across Disciplines, Issues and Scales (Part 2), Modsim 2001 International Congress on Modeling and Simulation, Modeling and Simulation Society of Australia and New Zealand, Canberra, pp. 673-678.

Jose, A. M. and Cruz, N. A. (1999), "Climate change impact and responses in Philippines: water resources", Climate Research, Vol. 12, pp. 77-84.

Krol, M. S. and Bronstert, A. (2007), "Regional integrated modeling of climate change impacts on natural resources and resource usage in semi-arid northeast Brazil", Environmental Modeling and Software, Vol. 22, pp. $259-268$.

Kwadijk, J. and Rotmans, J. (1995), “The impact of climate change on river Rhine: a scenario study”, Climatic Change, Vol. 30, pp. 397- 425.

Labat, D., Godderis, Y., Probst, J. L. and Guyot, J. L. (2004), "Evidence for global runoff increase related to climate warming”, Advances in Water Resources, Vol. 27, pp. 631-642.

Lettenmaier, D. P., Wood, A. W., Palmer, R. N., Wood, E. F. and Stakhiv, E. Z. (1999), "Water resources implications of global warming: a U. S. regional perspective”, Climatic Change, Vol. 43, pp. 537-579.

Leung, L. R., Qian, Y., Bian, X., Washington, W. M., Han, J. and Roads, J. O. (2004), "Mid century ensemble regional climate change scenarios for the western United States", Climatic Change, Vol. 62, pp 75-113.

Lowe, J. A. and Gregory, J. M. (2005), "The effects of climate change on storm surges around the United Kingdom”, Philosophical Transactions of Royal Society A, Vol. 363, pp. 1313-1328.

McBean, E. and Mottie, H. (2008), "Assessment of impact of climate change on water resources: a long term analysis of Great Lakes of north America”, Hydrology and Earth System Sciences, Vol. 12, pp. 239-255.

Meehl, G. A. (1996), "Vulnerability of freshwater resources to climate change in the tropical Pacific region", Water, Air, and Soil Pollution, Vol. 92, pp. 203-213.

Mimikou, M. A., Hadjisavva, P. S., Kouvopoulos, Y. S. and Afrateos, H. (1991), "Regional climate change impacts: ii. impacts on water management works", Hydrological Sciences-Journal-des Sciences Hydrologiques, Vol. 36, No. 3, pp. 259-270.

Neff, R., Chang, H., Knight, C. G., Najjar, R. G., Yarnal, B. and Walker, H. A. (2000), "Impact of climate variation and change on Mid-Atlantic region hydrology and water resources", Climate Research, Vol. 14, pp. 207-218.

Nemec, J. and Schaake, J. (1982), "Sensitivity of water resource systems to climate variation", Hydrological Sciences-Journal-des Sciences Hydrologiques, Vol. 27, No.3, pp. 327-343.

New, M. (2002), "Climate change and water resources in the southwestern Cape, South Africa", South African Journal of Science, Vol. 98, pp. 1-8.

Nicholls, R. J. (1995), “Coastal megacities and climate change”, GeoJournal, Vol.37, No.3, pp. 369-379.

Palutikof, J. P. (1987), "Some possible impacts of green house gas induced climate change on water resources in England and Wales", in The Influence of Climate Change and Climate Variability on the Hydrologic Regime and Water Resources, Proceedings of Vancouver Symposium, 1987, IAHS Publication No. 168, pp. 585-596.

Payne, J. T., Wood, A. W., Hamlet, A. F., Palmer, R. N. and Lettenmaier, D. P. (2004), "Mitigating the effects of climate change on the water resources of the Columbia river basin", Climatic Change, Vol. 62, pp. 233-256.

Pike, R. G., Spittlehouse, D. L., Bennett, K. E., Eginton, V. N., Tschaplinski, P. J., Murdock, T. Q. and Werner, A. T. (2008), "Climate change and watershed hydrology: part-ii hydrologic implications for British Columbia", Streamline Watershed Management Bulletin, Vol. 11, No.2, pp. 8-13.

Plummer, D. A., Caya, D., Cote, F. H., Giguere, M., Paquin, D., Biner, S., Harvey, R., De Elia, R. (2006), "Climate and climate change over north America as simulated by the Climate, Vol. 19, pp. 3112-3132. 
Rani, D., Moreira, M. M. and Maurato, S. (2008), "Preliminary analysis of Alvito-Odivelas reservoir system operation under climate change scenarios", in Lopez-Francos, A. (ed.), Proceedings of Drought Management: Scientific and Technological Innovations Conference in Zaragoza, Spain, 2008, Options Mediterraneennes, Series A, No. 80, pp. 133-138.

Rodriguez da Silva, V. D. P. (2004), "On climate variability in northeast of Brazil”, Journal of Arid Environments, Vol. 58, pp. 575-596.

Rogers, P. (1994), “Assessing socio-economic consequences of climate change on water resources", Climatic Change, Vol. 28, pp. 179-208.

Rosenzweig, C., Strzepek, K. M., Major, D. C., Iglesias, A., Yates, D. N., McCluskey, A. and Hillel, D. (2004), "Water resources for agriculture in a changing climate: international case studies", Global Environmental Change, Vol. 14, pp. 345-360.

Simonovic, S. P. (2003), "Methodology for assessment of climate change impacts on large scale flood protection system", Journal of Water Resources Planning and Management, Vol. 129, No.5, pp. 361-371.

Tao, F., Yokozawa, M., Hayashi, Y. and Lin, E. (2003), "Future climate change, the agricultural water cycle and agricultural production in China", Agriculture, Ecosystems and Environment, Vol. 95, pp. 203-215.

Tao, F., Yokozawa, M., Hayashi, Y. and Lin, E. (2005), “A perspective on water resources in China: interaction between climate change and soil degradation”, Climatic Change, Vol. 68, pp. 169-197.

Tarekegn, D. and Tadege, A, "Assessing the impact of climate change on the water resources of the Lake Tana sub basin using watbal model”, Research Project Report of GEF funded project: Climate Change Impacts on and Adaptation of Agro Ecological Systems in Africa Submitted at Centre for Environmental Economics and Policy in Africa (CEEPA), University of Pretoria, Pretoria, Available at: http://www.ceepa.co.za/uploads/files/CDP30.pdf

Wuebbles, D. J. and HayHoe, K. (2004), "Climate change predictions for the United States midwest", Mitigation and Adaptation Strategies for Global Change, Vol. 9, pp. 335-363.

Wurbs, R. A., Muttiah, R. S. and Felden, F. (2005), "Incorporation of climate change in water availability modeling", Journal of Hydrologic Engineering, ASCE, Vol. 10, No. 5, pp. 375-385.

$\mathrm{Xu}$, C. Y. (2000), "Modeling of effect of climate change on water resources in central Sweden", Water Resources Management, Vol. 14, pp. 177-189.

$\mathrm{Xu}$, Z. X., Chen, Y. N. and Li, J. Y. (2004), "Impact of climate change on water resources in the Tarim river basin”, Water Resources Management, Vol. 18, pp. 439-458.

Yu, P. S., Yang, T. C. and Wu, C. K. (2002), "Impact of climate change on water resources in southern Taiwan", Journal of Hydrology, Vol. 260, pp. 161-175.

Zeid, E. B. and El-Fadel, M. (2002), "Climate change and water resources in Lebanon and the middle east", Journal of Water Resources Planning and Management, ASCE, pp. 343-355.

Zeng, N., Ding, Y., Pan, J., Wang, H. and Gregg, J. (2008), "Climate change the Chinese challenge”, SCIENCE, Vol. 319, pp. 730-731. 